Responsabilité rédactionnelle: FMH SERVICES

\title{
Verständnis
}

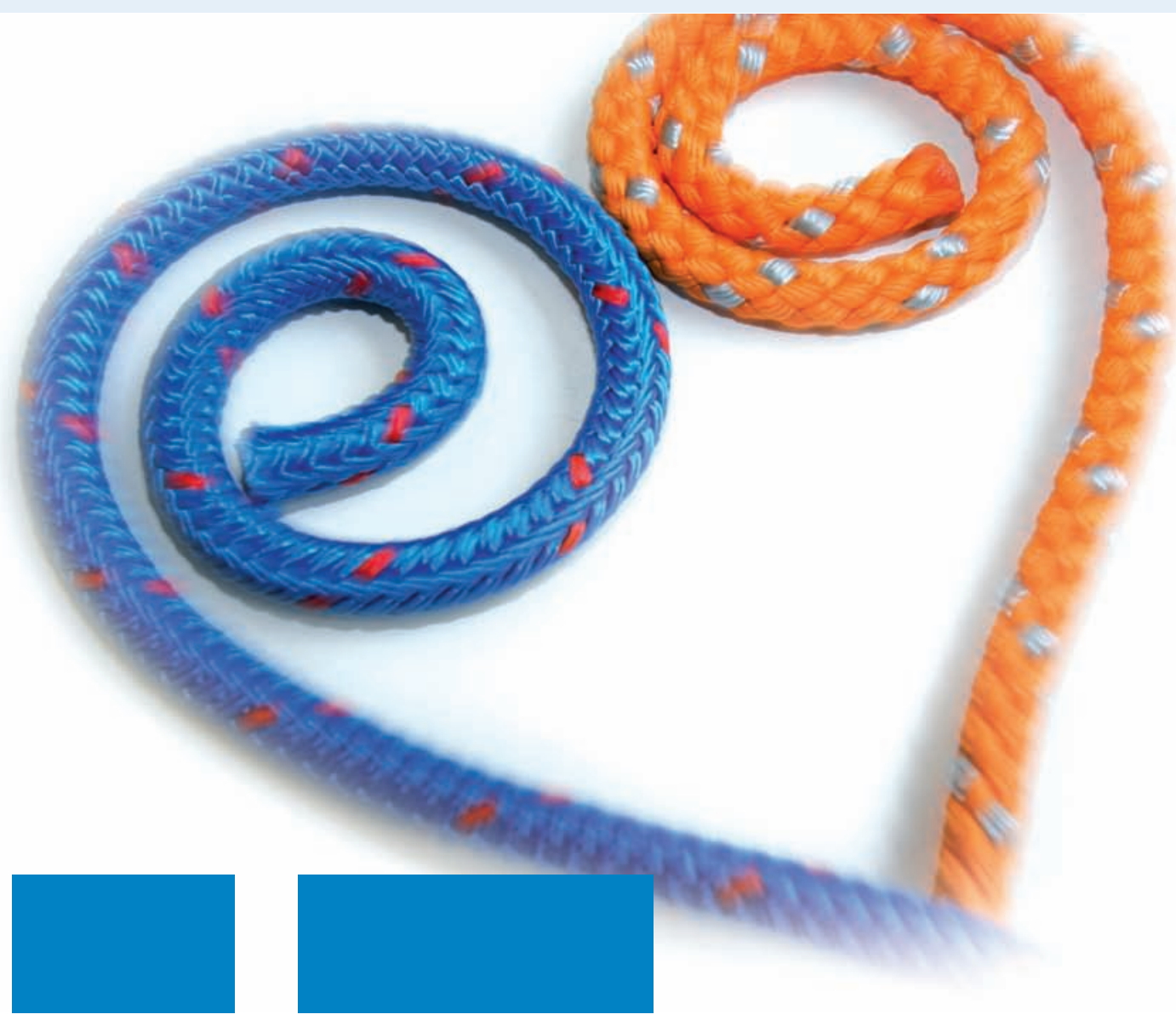

Für schwierige Situationen haben wir Verständnis. Einfühlsam und bestimmt finden wir die optimale Lösung. Über das uns entgegengebrachte Vertrauen der Ärzte und Zahnärzte freuen wir uns sehr. Wir unterstützen Sie als kompetenter und zuverlässiger Partner in allen Inkasso-Angelegenheiten. Unser motiviertes Team wird sich auch in Zukunft voll für Sie einsetzen. Unser Erfolg ist Ihr Erfolg.

Name / Vorname

Adresse

PLZ / Ort

Tel. Privat / Geschäft

Ich wünsche eine persönliche Beratung

Senden Sie mir Ihre Inkasso Dokumentation

powered by InKaS

Antworttalon: Bitte einsenden oder per Fax: 0323443966

\section{FMH INKASSO}

Inkassostelle Encath AG Koordinationsstelle Postfach $800 \square 2501$ Biel

Telefon 0323443969 Fax 0323443966 mail@fmhininkasso.ch $\square$ www.fmhinkasso.ch 